\title{
Comparative Study of Structural and Optical Properties of SiO2 Nanoparticles Prepared by DC Reactive Sputtering and Sol-Gel Route
}

Nora H. Mutesher

University of Baghdad Al-Jaderyia Campus College of Science

Firas Jawad Kadhim ( $\sim$ dr.firas1990@yahoo.com )

University of Baghdad

Original Research

Keywords: Silicon dioxide, nanostructures, Reactive magnetron sputtering, Sol-gel

Posted Date: February 8th, 2021

DOl: https://doi.org/10.21203/rs.3.rs-157088/v1

License: (c) (i) This work is licensed under a Creative Commons Attribution 4.0 International License.

Read Full License 


\section{Abstract}

In the present work, silicon dioxide $\left(\mathrm{SiO}_{2}\right)$ nanostructures were synthesized using two different techniques: sol-gel deposition and dc reactive plasma sputtering deposition. Amorphous structural phase of silica films was observed for the samples synthesized by two decomposition methods. The results of scanning electron microscopy indicated the nanostructural characteristic of such compounds. In addition to, the dependence of such nanostructures on the synthesis parameters in each preparation method. The FT-IR spectroscopic measurements showed the formation of siloxan bonds as well as the high content of hydroxyl groups in silica sol-gel samples compared with samples derived sputtering. The UV-Vis. Spectroscopic measurements were used to investigate the optical properties of such nanostructure films in order to select the optimum samples that can be employed in different optoelectronics applications such as scatters in amplifying media.

\section{Introduction}

In recent years, nanoparticles have been studied intensively due to their outstanding properties that make them suitable for various applications including catalysts, humidity sensors, pigments and pharmacy [1, 2]. Among numerous nanostructured materials, silica has occupied a prominent position both in scientific researches and industrial applications because of its ease of preparation and wide range of uses such as anti-resistance, corrosion resistance, hardness, dielectric, optical transparency [3-5].

The synthetic silica (colloidal silica, silica gels, pyrogenic silica, and precipitated silica), which is pure and produced mostly in amorphous powder forms compared to natural mineral silica (quartz, tridymite, cristobalite) which are in crystalline forms [6].

A variety of physical and chemical deposition methods have been utilized to synthesize $\mathrm{SiO}_{2}$ nanostructure thin films such as dc reactive magnetron sputtering [7-10], spray deposition [11], anodization [12] and sol-gel [13-16]. Among these methods, sol-gel process is wet-chemical technique; the thickness of coating the sol-gel method can be controlled by changing the composition and the viscosity of sol. Furthermore, the final product might be shaped into several structural forms by controlling gelation conditions and can be supported with different materials. Sol-gel is usually prepared amorphous phase with drying to degrees of $250{ }^{\circ} \mathrm{C}$, there are a number of factors that influence the final product of Sol-gel such as $\mathrm{pH}$, molar ratios $(\mathrm{R})$ of reactants, solvents, temperature and time [17].

On the other hands, the reactive magnetron sputtering technique is a very interesting for industries for many reasons: metal targets are used, a uniform thin film with controllable surface state and morphology [18] and a large-scale production is possible [19]. There are many parameters that effect of sputtering technique such as gas pressure, substrate biasing, electrical power.

The aim of the present work is to compare the optical and structural properties of silica nanoparticles that produced by using two different techniques; sol-gel rout and magnetron plasma sputtering. Thus, the 
characteristics that make these particles applicable in different technological applications can be determined.

\section{Experimental Part}

The Synthesis of Silica film by the sol-gel method includes the steps in which TEOS and ethanol were mixed at molar ratio of 1:4 to prepare the first solution. The catalyst solution was contained deionized water of unity $\mathrm{pH}$ (using $0.15 \mathrm{M}$ of hydrochloric acid $\mathrm{HCl}$ ) mixed with ethanol at molar ratio of 2:4. The catalyst solution was added drop by drop to the first solution to from the final sol. Finally, $0.5 \mathrm{ml}$ of N,N dimethaylformamide was then added to the final sol as drying control chemical additive, then casting in a covered glass tube at $60^{\circ} \mathrm{C}$ aging for 2 hour. $\mathrm{SiO}_{2}$ thin films were prepared using spinning decomposition method by drops the sol onto glass substrate with spinning speed of $3500 \mathrm{rev} / \mathrm{min}$. by spin coating device and then the films obtained are dried at $60^{\circ} \mathrm{C}$ for 2 hours.

The synthesis of Silica films using dc closed-field unbalanced magnetron (CFUBM) plasma sputtering includes the following details; the deposition chamber was made of stainless steel and Silicon sheet high purity $(99.99 \%)$ was connected to the cathode, also made of stainless steel, as a target and the anode as holder of substrate. The operation conditions of this sputtering configuration include total gas pressure, inter-electrode distance, gas mixing ratio and gas flow rate. Varying discharge voltage was almost possible during the operation. The chamber was evacuated using a rotary pump. In the chamber, after reaching the operating pressure of $10^{-2} \mathrm{mbar}$, argon and oxygen were introduced and the plasma was turned on for discharge current $40 \mathrm{~mA}$, discharge voltage $2.5 \mathrm{kV}$ and deposition time of 3 hours.

The structural and optical properties of silica film samples, which prepared from the two techniques, were studied through XRD, scanning electron microscopy, FTIR spectroscopy and UV-VIS spectroscopy.

\section{Result And Discussion}

The x-ray diffraction (XRD) analysis was carried out on the prepared samples and typical diffraction patterns are shown in Fig. (1). It's clearly observed that the prepared samples, by both methods, have amorphous phase structure because the X-ray diagrams did not display patterns arising from the crystalline phases. This gives us an indication that such structures can be synthesized without any microstructures as defects.

The characteristic vibrational bands of silica were found in the FTIR spectra of the film samples as shown in Fig. (2). The FTIR spectra of silica obtained from plasma sputtering and sol-gel technique show common bands, curves 1 and 2 showed a broad band centered at $3400 \mathrm{~cm}-1$ attributed to stretching vibrations of the free silanol group Si-OH on surface of silica network [20]. The bands around 460 (466) $\mathrm{cm}^{-1}$ corresponds to the bending mode of Si-O-Si bond and the band around $\sim 802 \mathrm{~cm}^{-1}$ corresponds to the symmetric stretching mode of $\mathrm{Si}-\mathrm{O}-\mathrm{Si}$. The position and the shape of $\mathrm{Si}-\mathrm{O}$ vibrational band around 1072 (1063) cm-1 shows a stoichiometric silicon dioxide structure [21-23]. 
The broad peak around $3400 \mathrm{~cm}^{-1}$ due to the hydroxyl groups become weaker on heat treatment but become smaller after the crystallization around $500^{\circ} \mathrm{C}$, and then disappeared. We can deduce from the above figure that the plasma sputtering technology is better because of the clear structural homogeneity, high homogeneity, as well as lower $\mathrm{OH}$ groups, i.e. less porosity.

Figure (3) illustrates the UV-Visible absorption spectra of silica synthesized via sol-gel and dc closed-field unbalanced magnetron (CFUBM) plasma sputtering, the absorption edge of silica prepared by sol-gel is about $310 \mathrm{~nm}$ in UV range and in sputtering is about $400 \mathrm{~nm}$ in visible range. The nanoparticles' absorbance is highly dependent on the wavelength and Transparency or thickness. From Fig. (3), can see that the intensity of the absorption spectrum of pure $\mathrm{SiO}_{2}$ nanoparticles continuously decreases with the wavelength without any peaks [24, 25].

The band gap energy $\left(E_{g}\right)$ of the prepared samples were determined by the Tauc's equation:

$(a h v)^{1 / n}=B\left(h v-E_{g}\right)$

where $h$ is the Planck constant, $\mathrm{v}$ is the photon's frequency, $E_{\mathrm{g}}$ is the band gap energy, and $B$ is a constant. The $\mathrm{n}$ factor depends on the nature of the electron transition and is equal to $1 / 2$ or 2 for the direct and indirect transition band gaps, respectively [26]. The bandgap energy is $3.8 \mathrm{eV}$ in sputtering and $4.5 \mathrm{eV}$ in sol-gel as showed in Fig. (4), it is clearly seen that the band gap decreases in sputtering

The SEM micrographs in the Fig. (5a) shows $\mathrm{SiO}_{2}$ nanoparticles with magnification of $5000 \mathrm{KX}$ that preparation via sol-gel rout. The average particle size observed from SEM analysis is found to be 26.80 $\mathrm{nm}$. In Fig. (5b) show $\mathrm{SiO}_{2}$ nanoparticles that preparation by sputtering techniques. The average particle size was (18) $\mathrm{nm}$, as an advantage of sputtering technique in nanostructure fabrication, the aggregation over the prepared nanoparticles is relatively low [27]. We found the particle size in sputtering less than particle size in sol-gel.

\section{Conclusion}

Silicon dioxide films were prepared by closed-field unbalanced dc magnetron sputtering technique and sol-gel method. The sputtered films showed better optical and structural properties than the sol-gel deposited films due to their lower bandgap energies, high structural purity as only one peak was observed on the XRD patterns the vibration peaks of Si-O-Si and Si-O were appeared. SEM investigation evidence the nanoparticles with little agglomeration.

\section{Declarations}

\section{Funding}

This work did not any fund or financial support from any institution. 


\section{Conflicts of interest/Competing interests}

The authors declare that they do not have any conflict of interest related to this work.

\section{Availability of data and material}

The authors declare that all data and materials included in this manuscript are available.

Code availability (software application or custom code)

Not applicable

\section{Author contributions}

Both authors have worked on the experimental part of this work. They have collected and analyzed the results, and finally written the manuscript.

\section{Compliance with ethical standards}

The authors declare that this work was prepared to comply with ethical standards and there is no potential conflicts of interest. As well, authors declare that the research does not involve Human Participants and/or Animals. They did not need for any informed consent related to publication of their work.

\section{Acknowledgments}

All participants to any part of this work were acknowledged.

\section{Consent for Participate}

Authors declare their consent for participate.

\section{Consent for Publication}

Authors declare their consent for publication.

\section{References}

[1] Rao, K. S., El-Hami, K., Kodaki, T., Matsushige, K. \& Makino, K "A novel method for synthesis of silica nanoparticles" Journal of Colloid and Interface Science 289, 2005.

[2] Rahman, I. A., Vejayakumaran, P., Sipaut, C. S., Ismail, J., Abu Bakar, M., Adnan, R. \& Chee, C. K." Synthesis of silica nanoparticles by modified sol-gel process: The effect of mixing modes of the reactants and drying techniques" Journal of Ceramics International 50(3), 2006.

[3] Chrusciel, J. \& Slusarski, L. "Synthesis of nanosilica by the sol-gel method 
and its activity toward polymers" Journal of Materials Science 21 (4), 2003.

[4] KIM, K. \& KIM, D.H.T. "Formation of Silica Nanoparticles by Hydrolysis of TEOS Using a Mixed SemiBatch/Batch Method" Journal of SolGel Science and Technology 25, 2002.

[5] Tabatabaei, S., Shukohfar, A., Aghababazadeh, R. \& Mirhabibi, A. "Experimental study of the synthesis and characterisation of silica nanoparticles via the sol-gel method" Journal of Physics: Conference Series, 26, 2005.

[6] E. F. Vansant, P. V. D. Voort, and K. C. Vrancken "Characterization and Chemical Modification of the Silica Surface" Elsevier Science, New York, NY, USA, 1995.

[7] M. Radecka, M. Wierzbicka, S. Komornicki, M. Rekas "Influence of $\mathrm{Cr}$ on photoelectrochemical properties of $\mathrm{TiO}_{2}$ thin films" Physica B, 348, 2004.

[8] A. Gorzkowska, E. Kusior, M. Radecka, K. Zakrzewska" Visible photocurrent response of $\mathrm{TiO}_{2}$ anode" Surf. Sci. 600, 2006.

[9] A. Brudnik, A. Gorzkowska, E. Pamula, M. Radecka, K. Zakrzewska" Thin film $\mathrm{TiO}_{2}$ photoanodes for water photolysis prepared by dc magnetron sputtering" J. Power Sources, 173, 2007.

[10] M. Radecka, M. Rekas, A. Trenczek, K. Zakrzewska" Importance of the band gap energy and flat band potential for application of modified $\mathrm{TiO}_{2}$ photoanodes in water photolysis" J. Power Sources, 181, 2008.

[11] P.S. Shinde, S.B. Sadale, P.S. Patil, P.N. Bhosale, A. Brugerd, M. Neumann, C.H. Bhosale" Properties of spray deposited titanium dioxide thin films and their application in photoelectrocatalysis" Sol. Energy Mater. Sol. Cells, 92, 2008.

[12] W.K. Zhang, L. Wang, H. Huang, Y.P. Gan, C.T. Wang, X.Y. Tao" Light energy storage and photoelectrochemical behavior of the titanate nanotube array $/ \mathrm{Ni}(\mathrm{OH})_{2}$ electrode" Electrochim. Acta, 54 , 2009.

[13] J. Chen, Y. Zou, Y. Li, X. Zhou, J. Zhang, X. Li, X. Xiao, Y. Lin” "Improving the photoelectrochemical performance of polythiophene sensitized $\mathrm{TiO}_{2}$ electrode by modification with gold nanoparticles" Chem. Phys. Lett. 460, 2008.

[14] P.R. Mishra, P.K. Shukla, A.K. Singh, O.N. Srivastava" Investigation and optimization of nanostructured $\mathrm{TiO}_{2}$ photoelectrode in regard to hydrogen production through photoelectrochemical process" Int. J. Hydrogen Energy, 28, 2003.

[15] M. Bockmeyer, P. Lobmann" Densification and Microstructural Evolution of $\mathrm{TiO}_{2}$ Films Prepared by Sol-Gel Processing" Chem. Mater, 18, 2006. 
[16] P.R. Mishra, P.K. Shukla, O.N. Srivastava" Study of modular PEC solar cells for photoelectrochemical splitting of water employing nanostructured TiO2 photoelectrodes" Int. J. Hydrogen Energy, 32, 2007.

[17] T. Sugimoto, X. Zhou, A. Muramatsu" Synthesis of uniform anatase $\mathrm{TiO}_{2}$ nanoparticles by gel-sol method: 3. Formation process and size control"

J.Colloid Interf. Sci., 259, 2003.

[18] M. Matsuoka, M. Kitano, M. Takeuchi, K. Tsujimaru, M. Anpo, J.M. Thomas" Photocatalysis for new energy production: recent advances in photocatalytic water splitting reactions for hydrogen production" Catal. Today, 1222007.

[19] L. Dreesen, J.-F. Colomer, H. Limage, A. Gigue`re, S. Lucas” DC Magnetron Sputtering Deposition of Titanium Oxide Nanoparticles: Influence of Temperature, Pressure and Deposition Time on the Deposited Layer Morphology, the Wetting and Optical Surface Properties" Thin Solid Films, 6, 2009.

[20] Sotiropoulou S, Chaniotakis NA" Tuning the sol-gel microenvironment for acetylcholinesterase encapsulation" Biomaterials, 26, 2005.

[21] P. Paik, A. Gedanken, and Y. Mastai" Enantioselective Separation Using Chiral Mesoporous Spherical Silica Prepared by Templating of Chiral Block Copolymers" ACS Appl. Mater. Interfaces, 8, 2009.

[22] P. Paik, A. Gedanken, and Y. Mastai" Chiral separation abilities: Aspartic acid block copolymerimprinted mesoporous silica" Microporous Mesoporous Mater. 129, 2010.

[23] P. Paik, Y. Mastai, I. Kityk, P. Rakus, and A. Gedanken" Synthesis of amino acid block-copolymer imprinted chiral mesoporous silica and its acoustically-induced optical Kerr effects" J. Solid State Chem. 192, 2012.

[24] Ren Y., Zhao Y., Zhang Y., Tang W., Xin X., Shien J., Wang L., Facile synthesis of Au@SiO ${ }_{2}$ core-shell nanoparticles with multiple Au nanodots by a reverse microemulsion (water-in-oil) method,Colloids and Surfaces A: Physicochemical and Engineering Aspects 486, 2015.

[25] Veeranarayanan S., Poulose A. C., MO. S., Aravind A., Nagaoka Y., Yoshida Y., Maekawa T., Kumar D. S., FITC labeled silica nanoparticles as efficient cell tags: uptake and photostability study in endothelial cells, Journal of Fluorescence 22, 2011.

[26] Jacques I. Pankove., "Optical processes in semiconductors" Englewood Cliffs, New Jersey, PrenticeHall,1971.

[27] Hayder G. Fahad, Oday A. Hammadi, "Characterization of Highly-Pure Silicon Dioxide Nanoparticles as Scattering Centers for Random Gain Media” Iraqi Journal of Applied Physics, 16, 2020. 
[28] Mohammed A. Hameed, Zahraa M. Jabbar, "Preparation and Characterization of Silicon Dioxide Nanostructures by DC Reactive Closed-Field Unbalanced Magnetron Sputtering" Iraqi Journal of Applied Physics, 5, 2016.

\section{Figures}
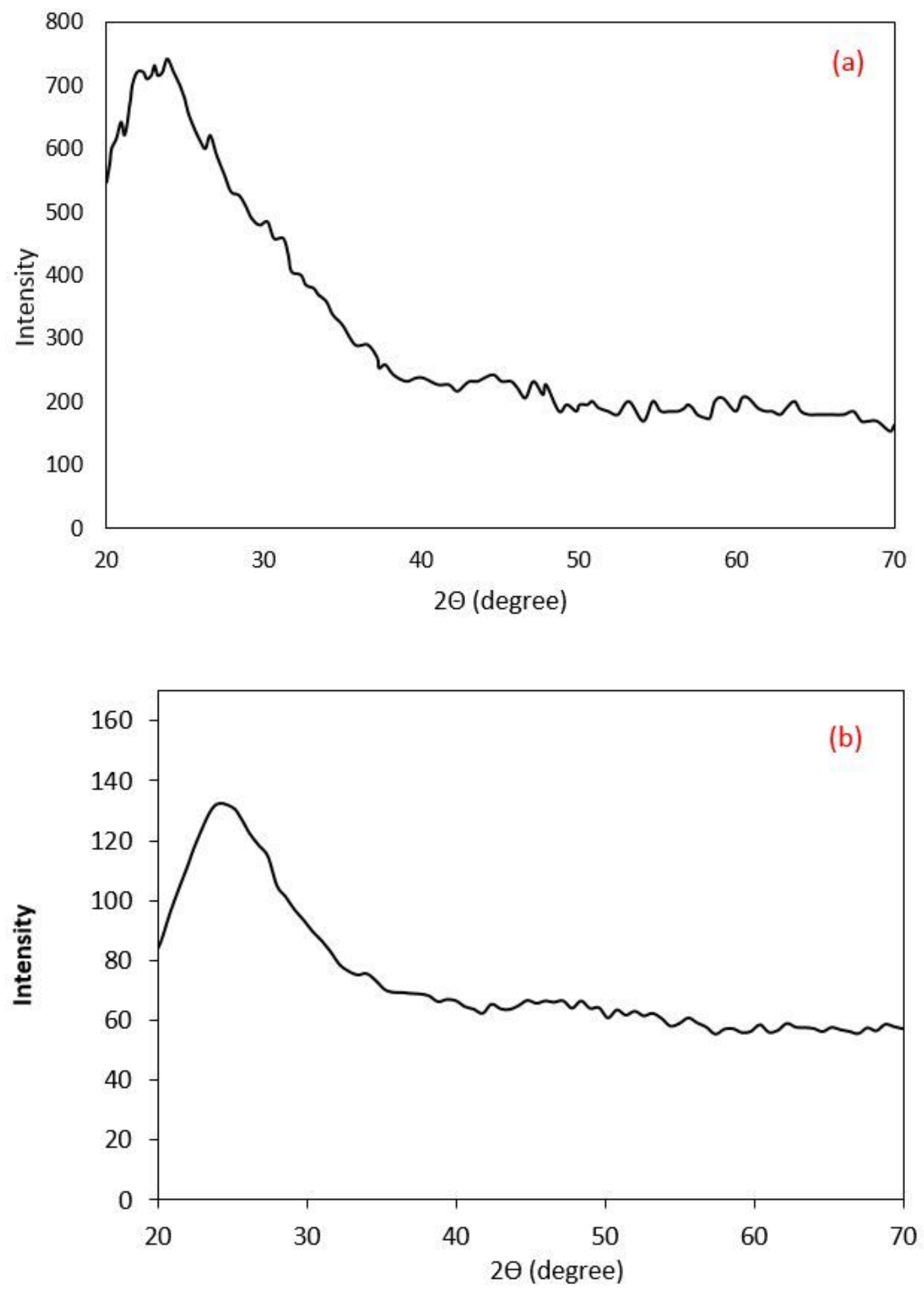

Figure 1 
XRD patterns of samples prepared by (a) CFUBM sputtering, and (b) sol-gel technique

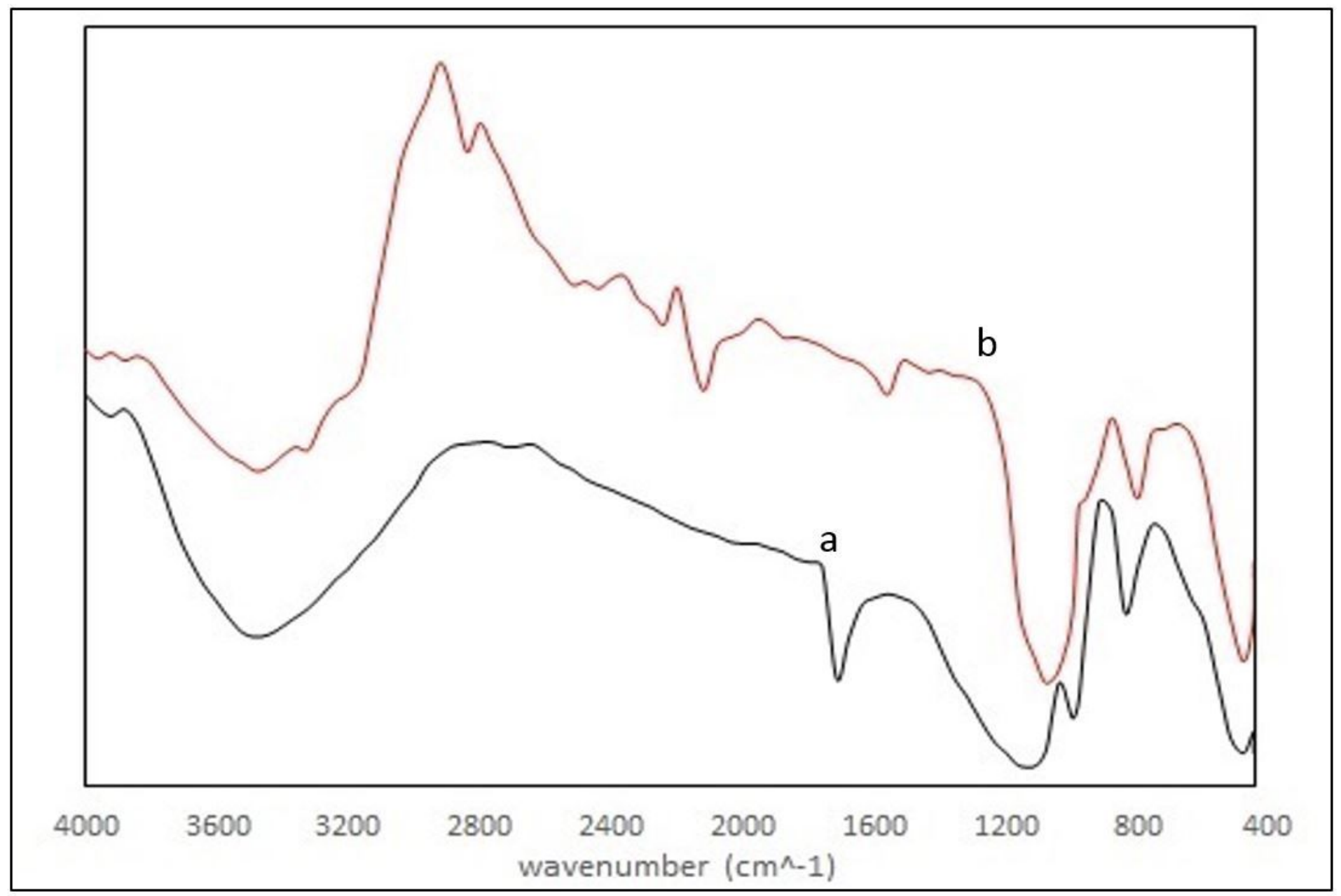

Figure 2

FTIR spectra of SiO2 nanoparticles prepared by (a) sol-gel technique, and (b) CFUBM sputtering 


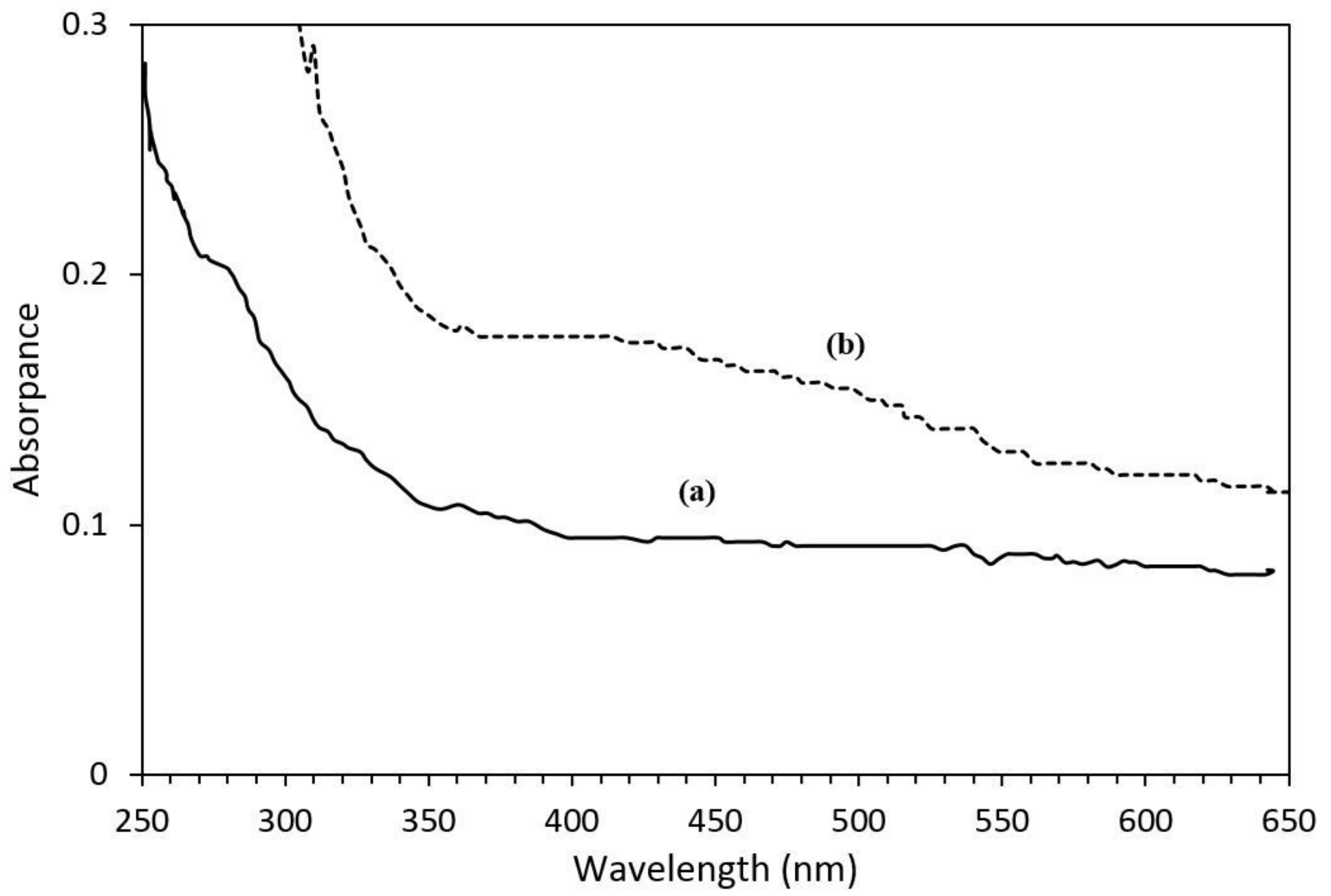

Figure 3

Absorption spectra of SiO2 nanoparticles prepared by (a) sol-gel technique, and (b) CFUBM sputtering 


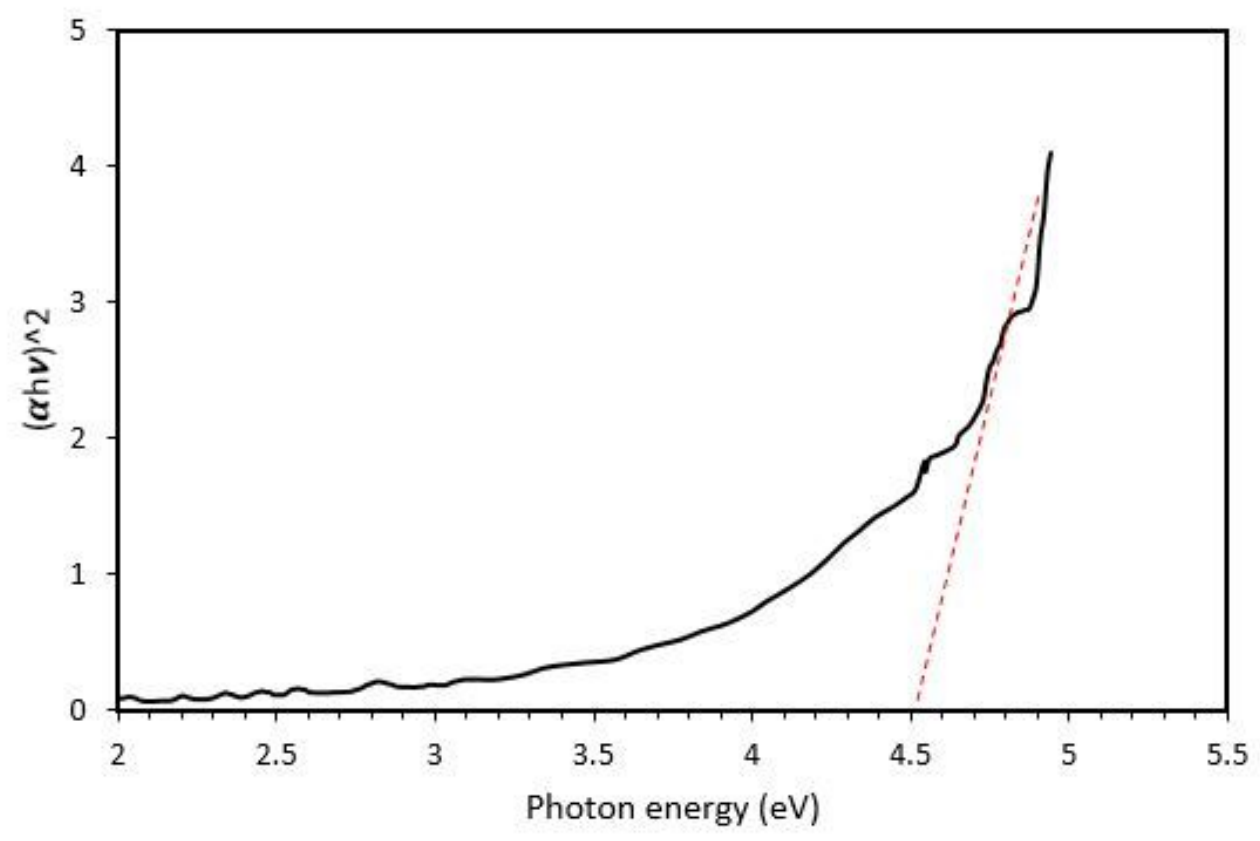

(a)

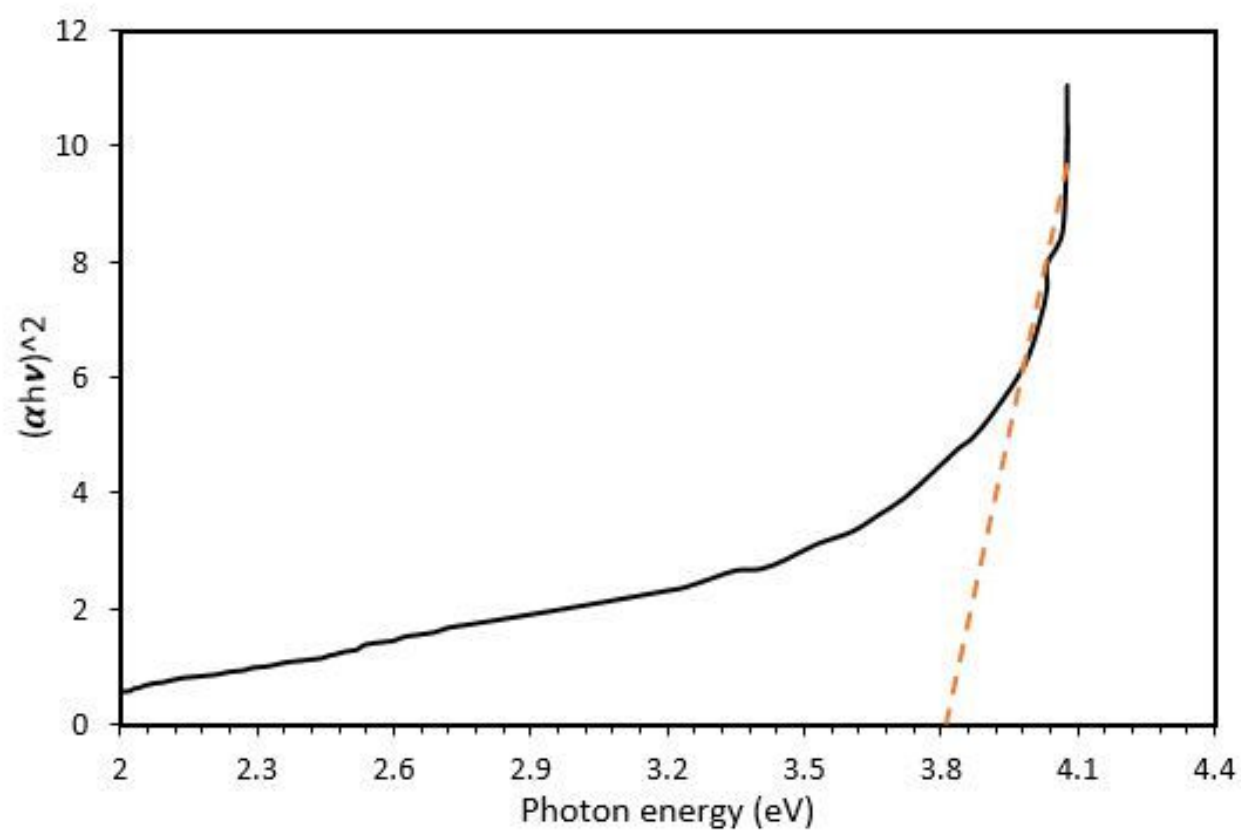

(b)

Figure 4

Determination of energy band gap of SiO2 nanoparticles prepared by (a) sol-gel technique, and (b) CFUBM sputtering 


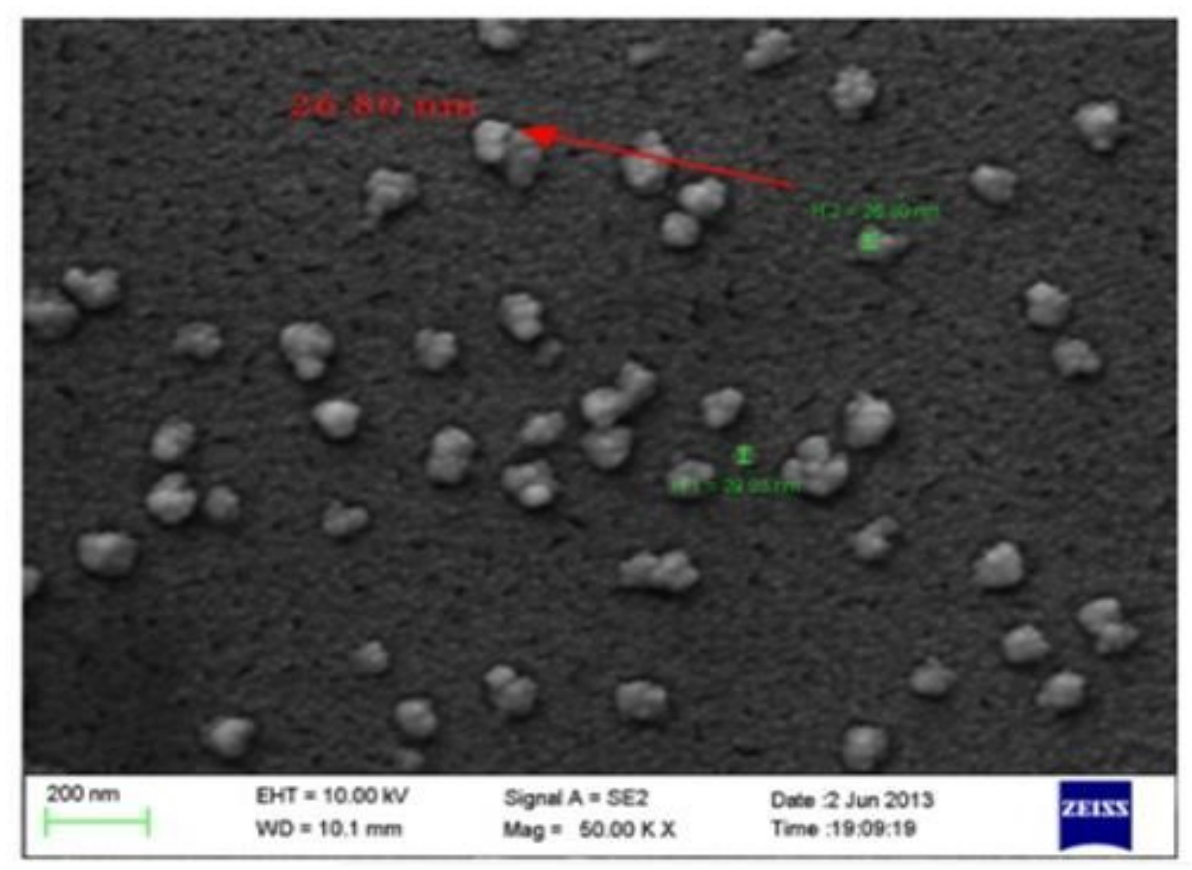

(a)

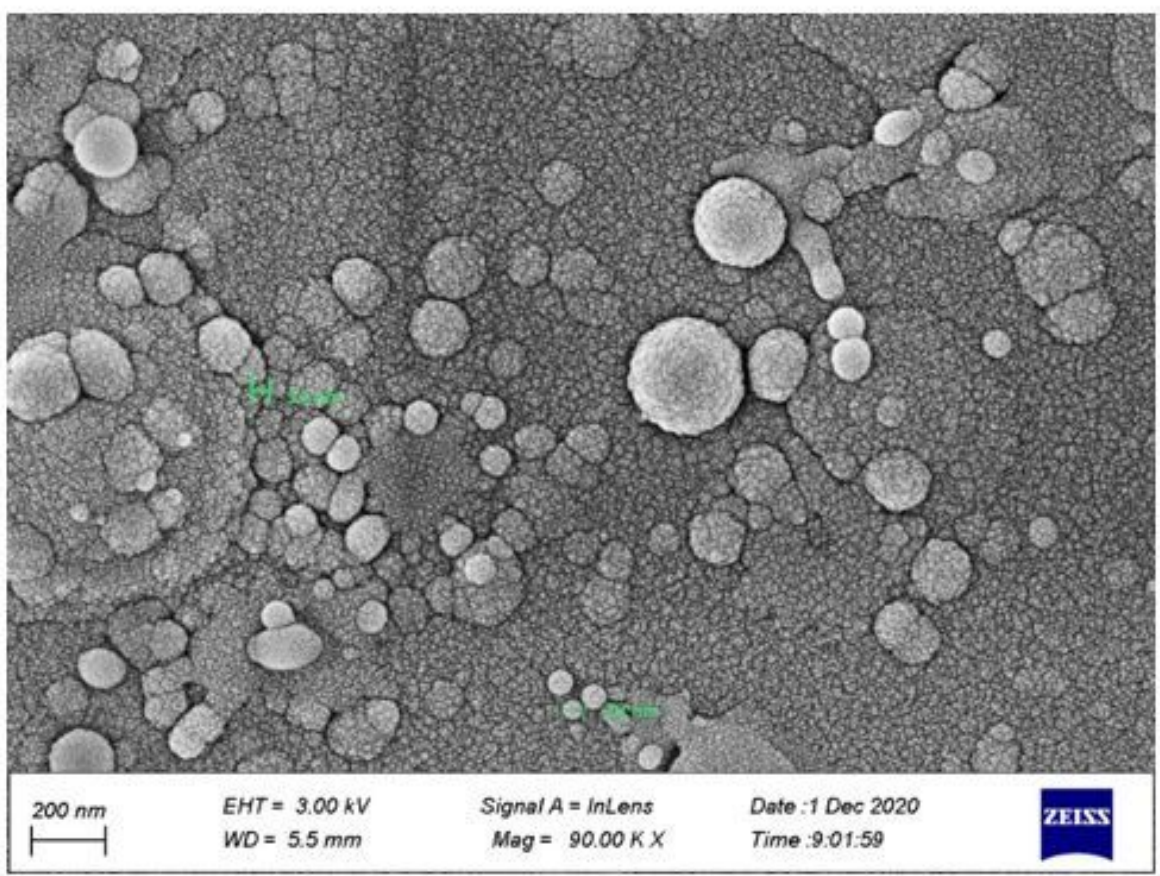

(b)

Figure 5

SEM images of SiO2 nanoparticles prepared by (a) sol-gel technique, and (b) CFUBM sputtering 